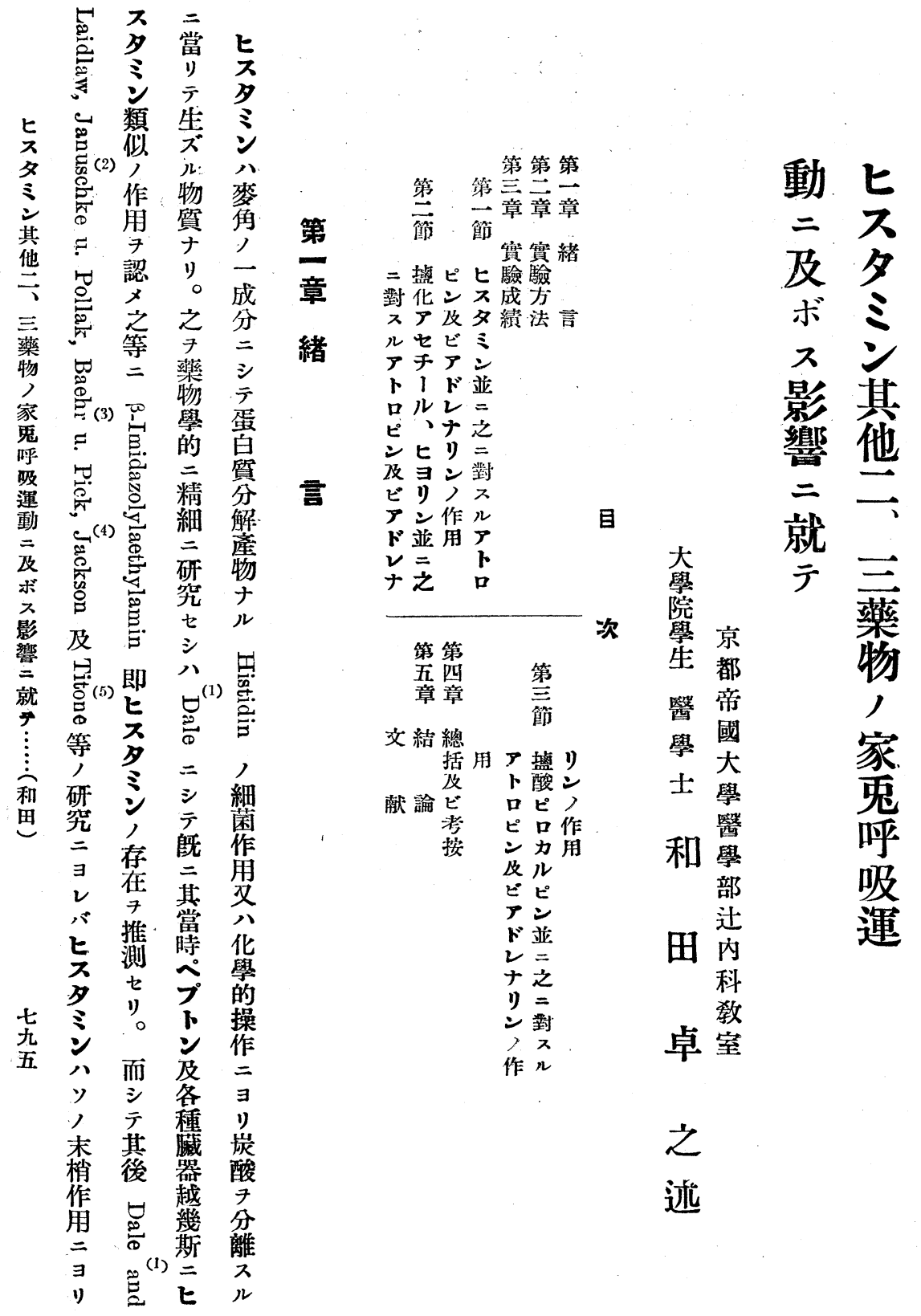




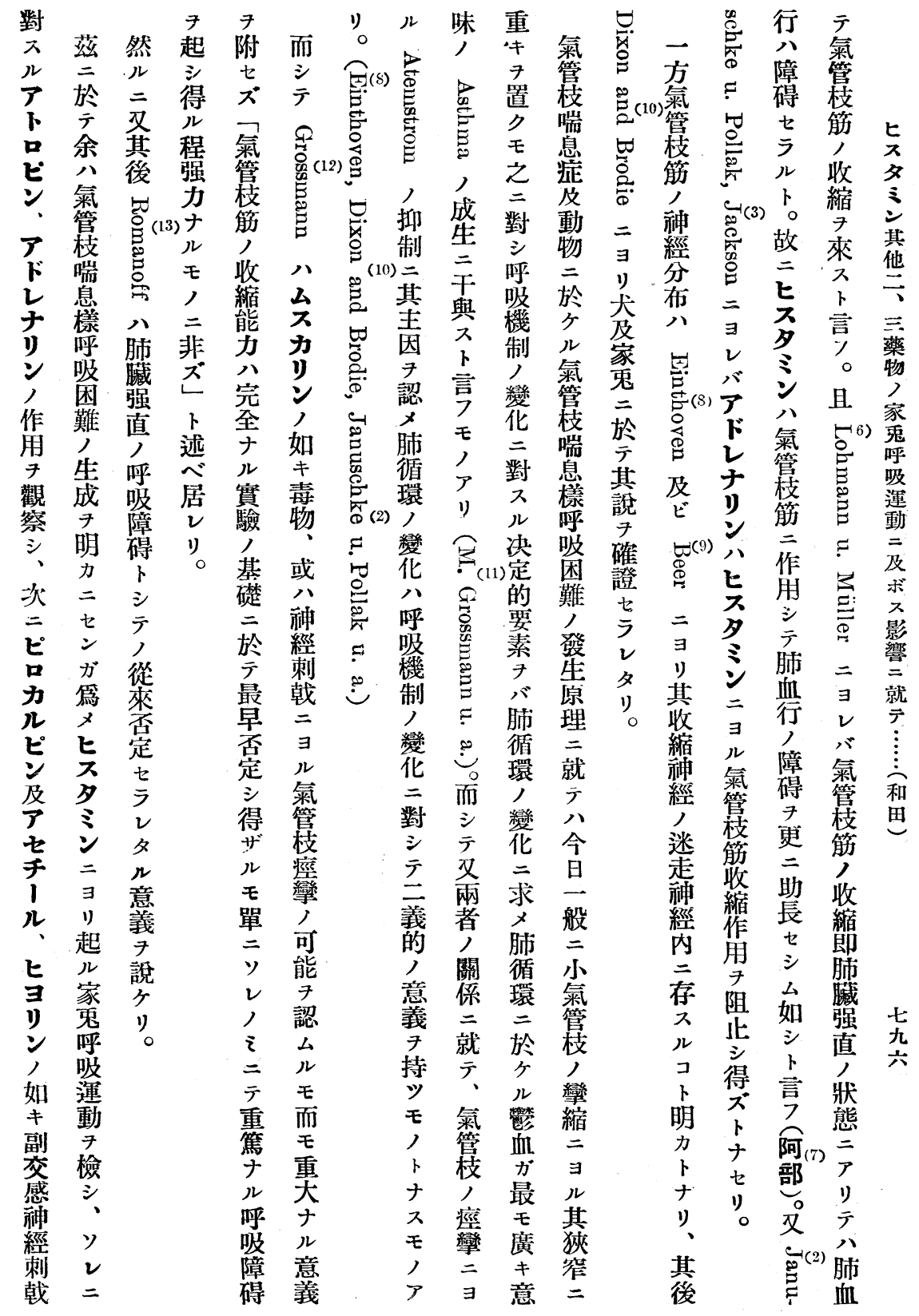




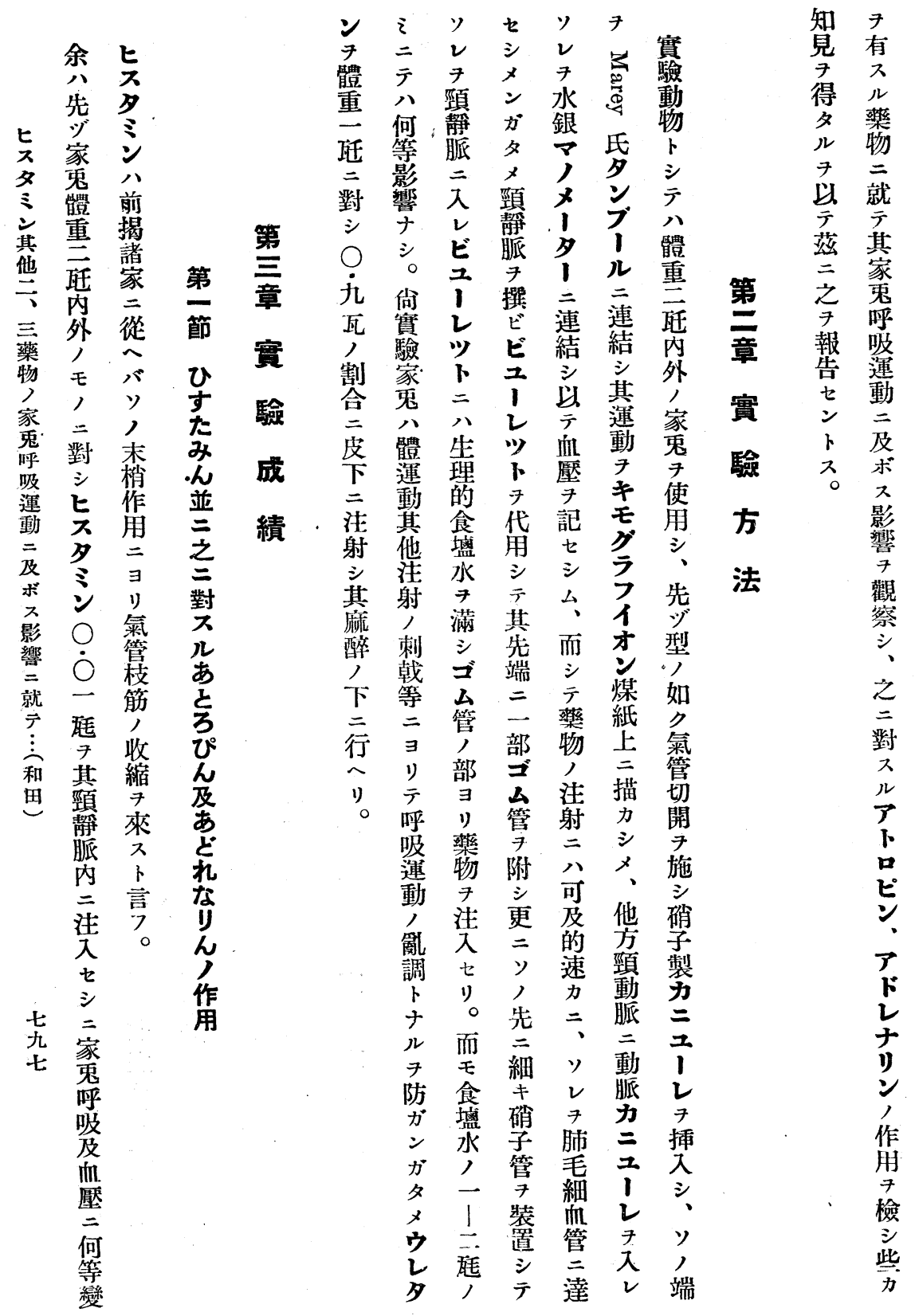




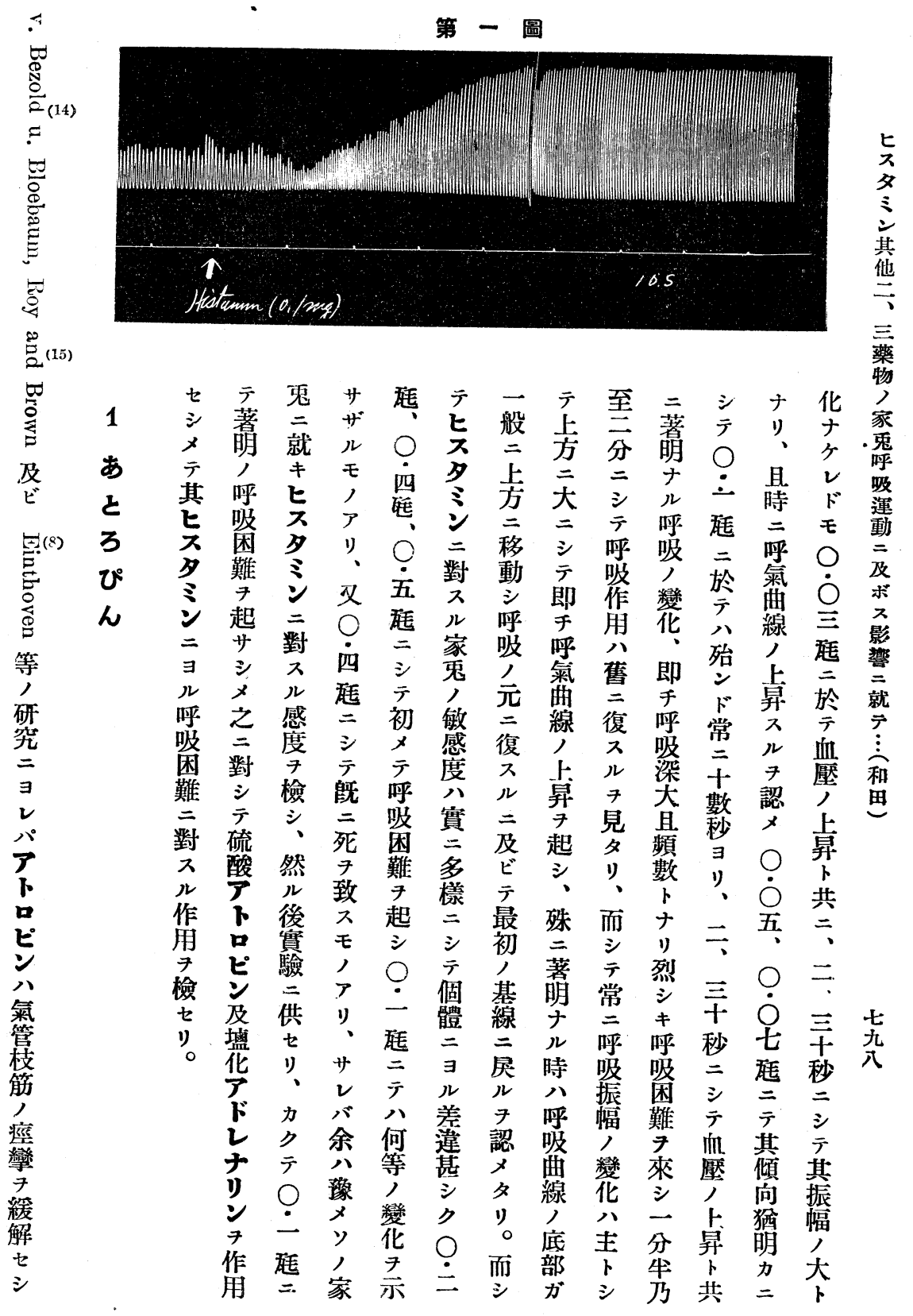




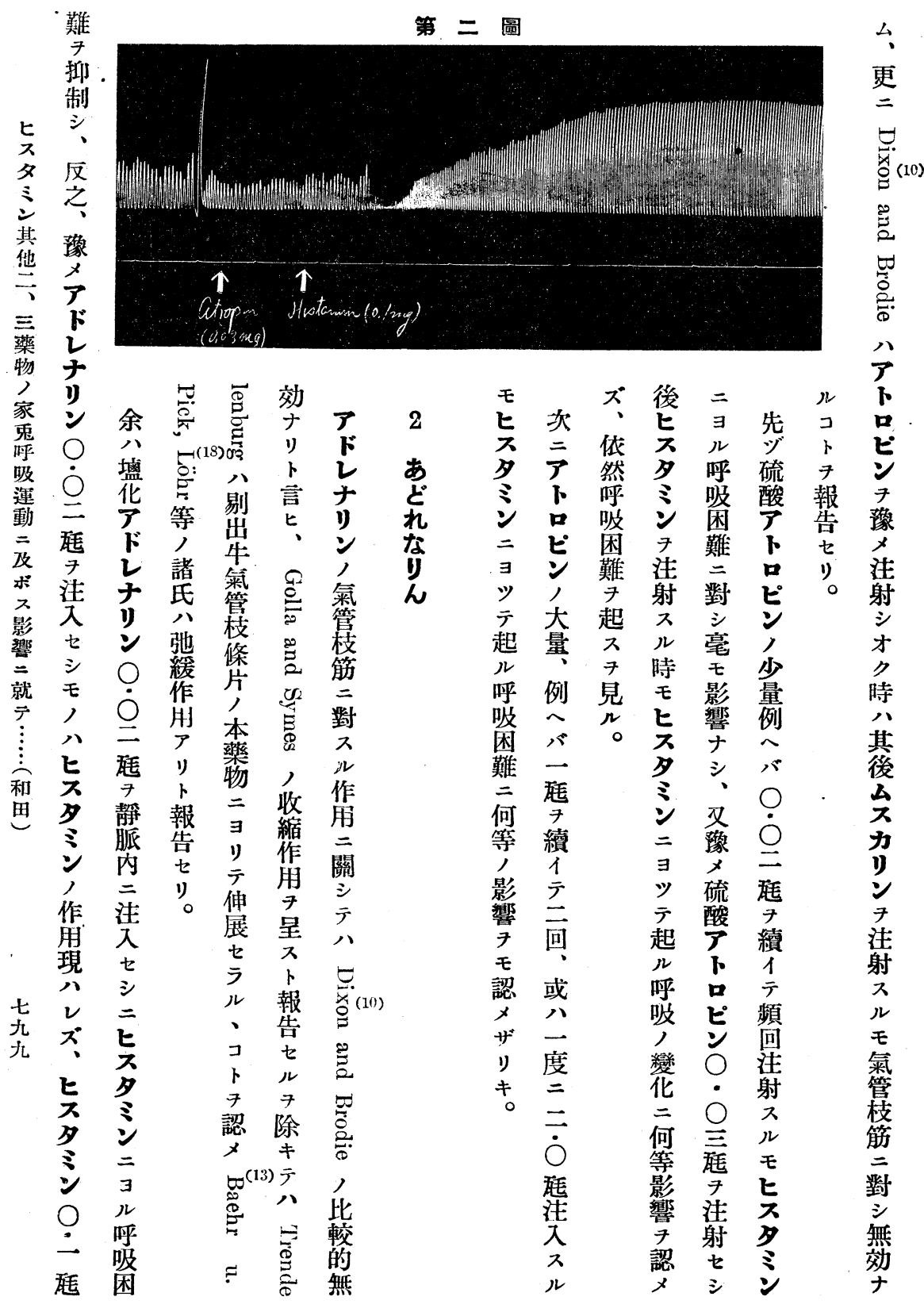




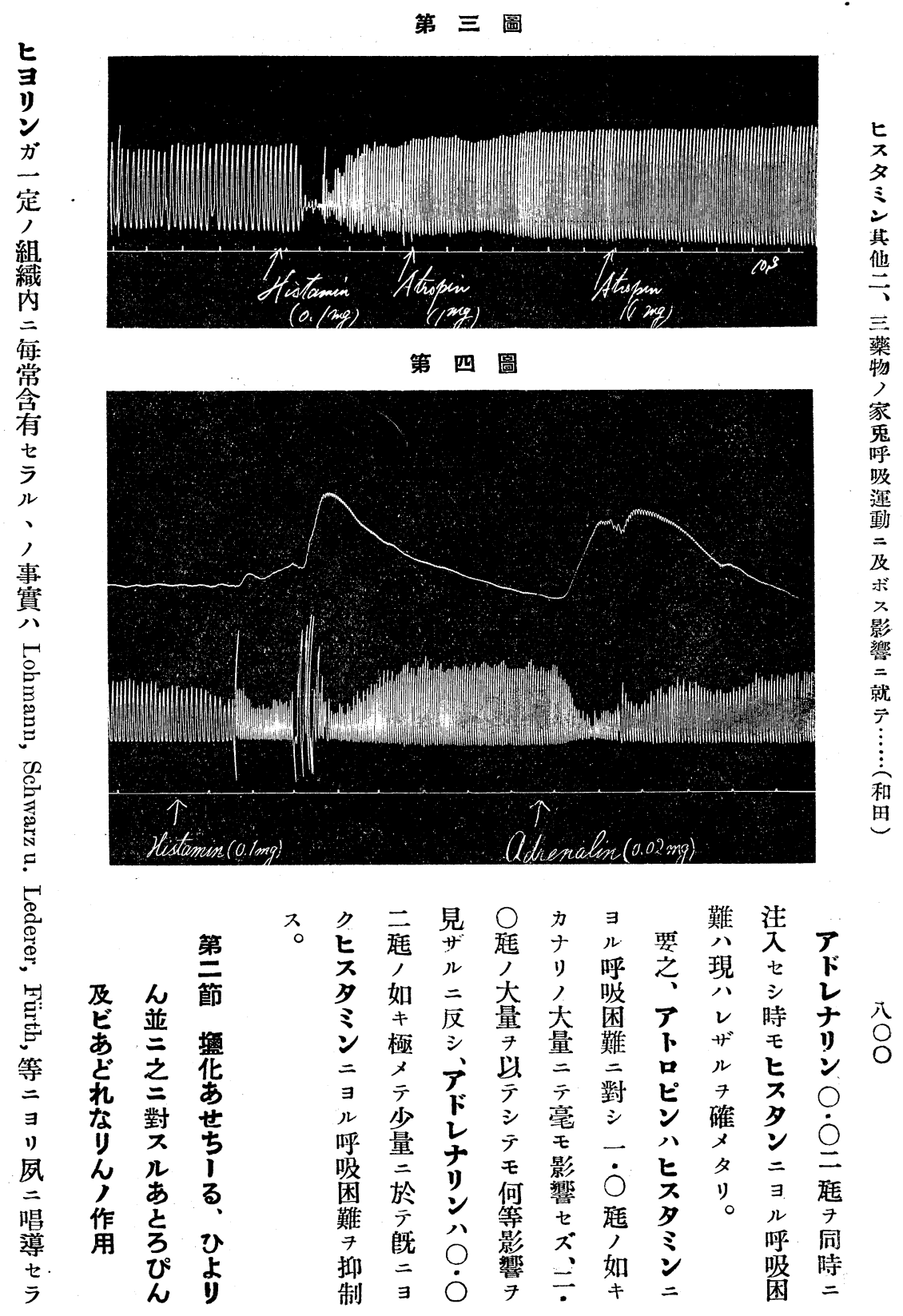




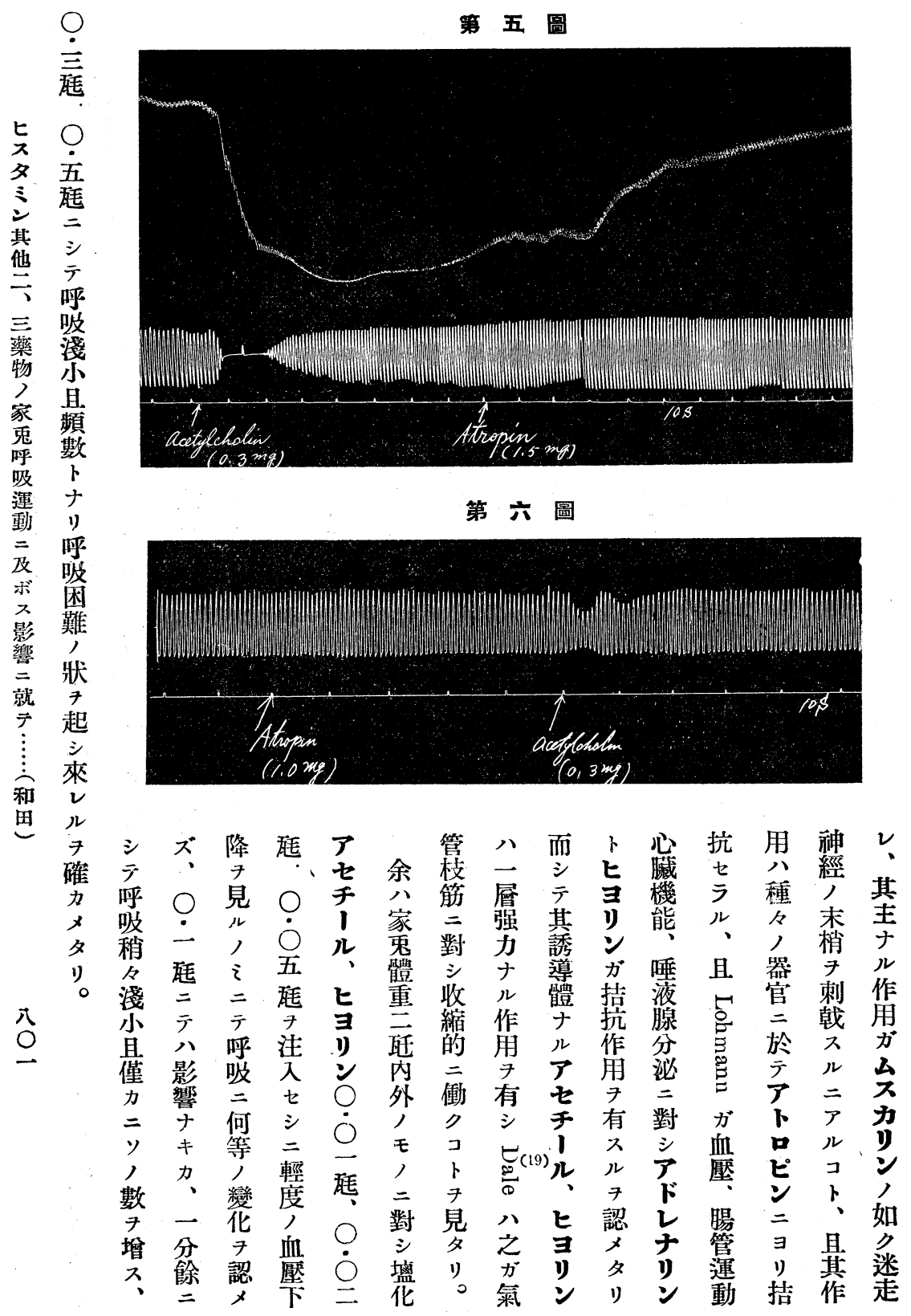


第 七 圖
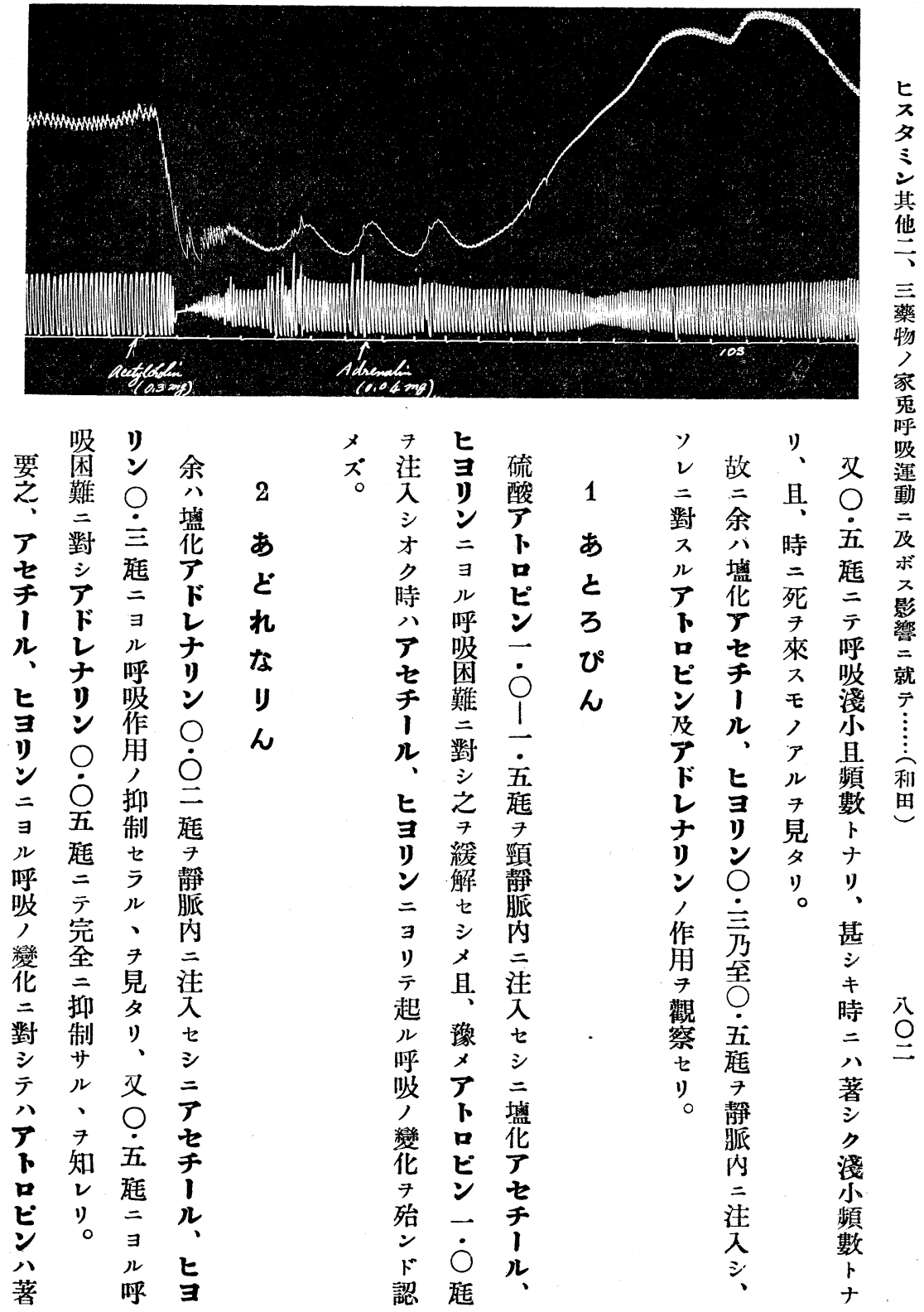
第八 圖

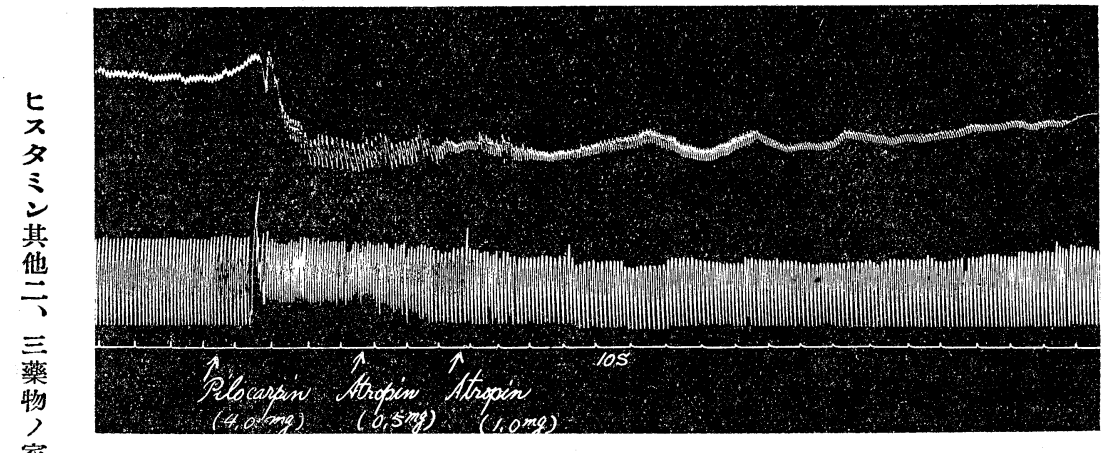

\begin{tabular}{|c|c|c|c|c|c|c|c|c|c|c|c|c|}
\hline & & $v$ & 層 & 注 & 靜 & タ & $\exists$ & & & & & 明 \\
\hline 硫 & 1 & 對 & $\begin{array}{l}\text { 璋 } \\
\text { 的 }\end{array}$ & 俞 & 脈 & ." & $\begin{array}{l}\text { ") } \\
\text { F }\end{array}$ & ビ & & 第 & 輕 & ナ \\
\hline$\vec{\gamma}$ & & $\pi$ & $=$ & $=$ & $=$ & 余 & 亲 & カ & & 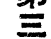 & ナ & 抑 \\
\hline $\boldsymbol{F}$ & あ & ル & シ & 比 & 注 & 忩 & 證 & $\pi$ & & 節 & נr & 制 \\
\hline 口 & $\varepsilon$ & $\vec{\gamma}$ & $\overline{5}$ & 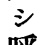 & 入 & 體 & 七 & ピ & & & 7 & 焦 \\
\hline $\begin{array}{l}E \\
y\end{array}$ & 3 & 占 & 淺 & 吸 & $\begin{array}{l}\text { シ } \\
\bar{テ}\end{array}$ & 重 & $\begin{array}{l}5 \\
2\end{array}$ & $\begin{array}{l}2 \\
=\end{array}$ & 及 & 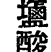 & 見 & 用 \\
\hline - & 70 & ピ & 且 & , & 何 & $\overrightarrow{\text { 䣶 }}$ & 其 & $\exists$ & あ & ぴ & y & 呈 \\
\hline$\dot{\theta}$ & o & $\bar{v}$ & 蘋 & 淺 & 等 & $\not \overrightarrow{B J}$ & 荇 & リ & $\varepsilon$ & 3 & $\circ$ & 茫 \\
\hline 0 & $\omega$ & 及 & 數 & 小 & 呼 & 外 & $\theta-1$ & $\bar{\Sigma}$ & れ & מ2 & & \\
\hline 䖯 & & $\underset{5}{3}$ & r & $\begin{array}{r}r \\
+\end{array}$ & $\begin{array}{l}\text { 吸 } \\
=\end{array}$ & 家 & $\tilde{\tilde{D}}^{(3)}$ & 氮 & な & 可 & & ド \\
\hline 注 & & $i$ & $v$ & $n$ & 戀 & 㖁 & $F$ & 㕝 & $\dot{\alpha}$ & L & & L \\
\hline 入 & & ナ & リ & 7 & 化 & $=$ & $?$ & 瘫 & ) & 並 & & ナ \\
\hline 七 & & y & 0 & 認 & t & 對 & بִּِ & 攣 & 作 & $\equiv$ & & У \\
\hline シ & & 2 & 故 & $x$ & ク & シ & $\frac{2}{\sqrt{4}}$ & 7 & 用 & 之 & & 2 \\
\hline 黨 & & 作 & 全 & タ & 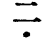 & 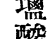 & $\exists_{11}$ & 設 & & 恝 & & fll \\
\hline$=$ & & 角 & 分 & , & 0 & Ło & 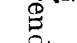 & $\hat{\jmath}$ & & 及 & & 制 \\
\hline 塭 & & 7 & - & 而 & 煌 & 口 & $\vec{\Phi}$ & ב & & $\pi$ & & 作 \\
\hline 酸 & & 檢 & $\because$ & シ & & カ & $\Xi$ & $r$ & & & & 用 \\
\hline E & & 七 & Y & T & $\equiv$ & $\pi$ & है & 八 & & 8 & & 무 \\
\hline カ & & $\circ$ & 四 & 14 & 0 & V & & $\Xi$ & & ぴ & & र \\
\hline$\pi$ & & & & 0 & 軞 & 0 & . & , & & L & & \\
\hline ビ & & & $\checkmark$ & 兓 & $=$ & $\dot{\boldsymbol{T}}$ & 䎖 & & & & & $E$ \\
\hline 2 & & & 㕶 & '́ & $\bar{\tau}$ & 五 & 음 & : & & & & 前 \\
\hline$\exists$ & & & 注 & 量 & q & 肔 & 筀 & & & & & \\
\hline リ & & & 䒘 & $=$ & カ & $\dot{\dot{x}}$ & z & 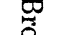 & & & & 比 \\
\hline 起 & & & シ & テ & $\pi$ & 0 & 7 & 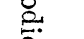 & & & & シ \\
\hline 》) & & & $\bar{\tau}$ & 八 & ビ & 毻 & 認 & & & & & \\
\hline シ & & & ' & - & 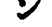 & 尹 & $x$ & $=$ & & & & \\
\hline
\end{tabular}


第九 圆
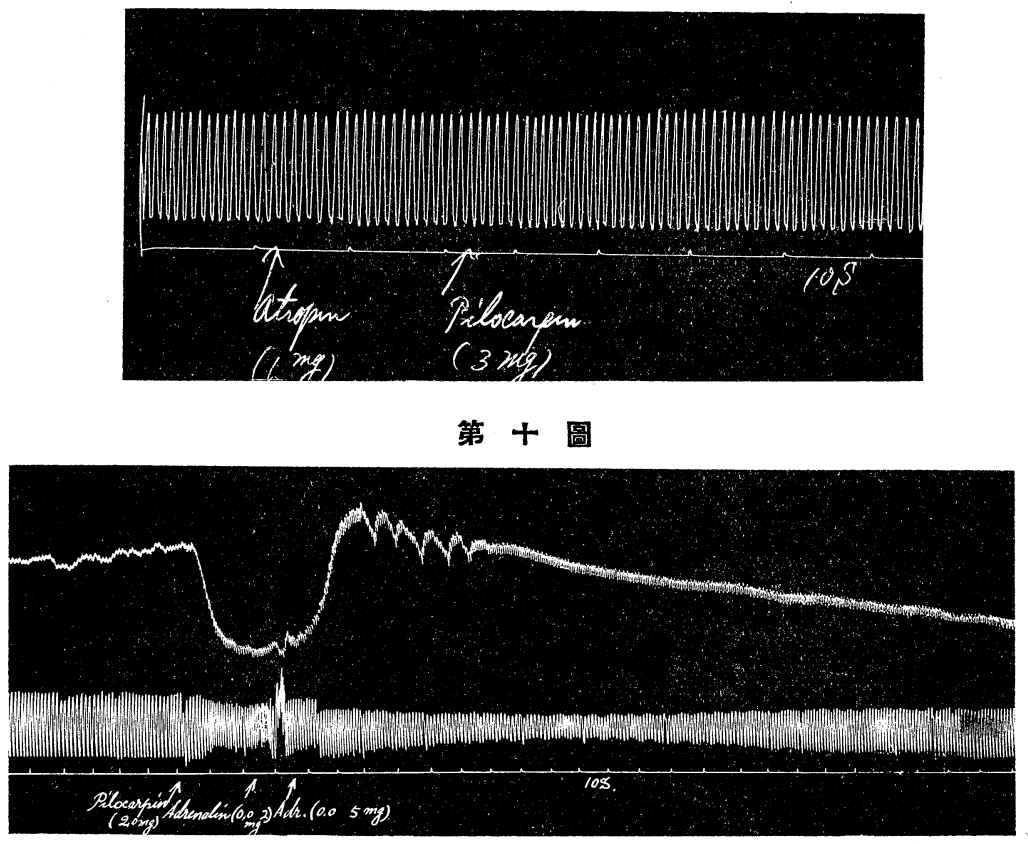

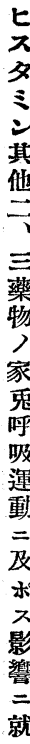

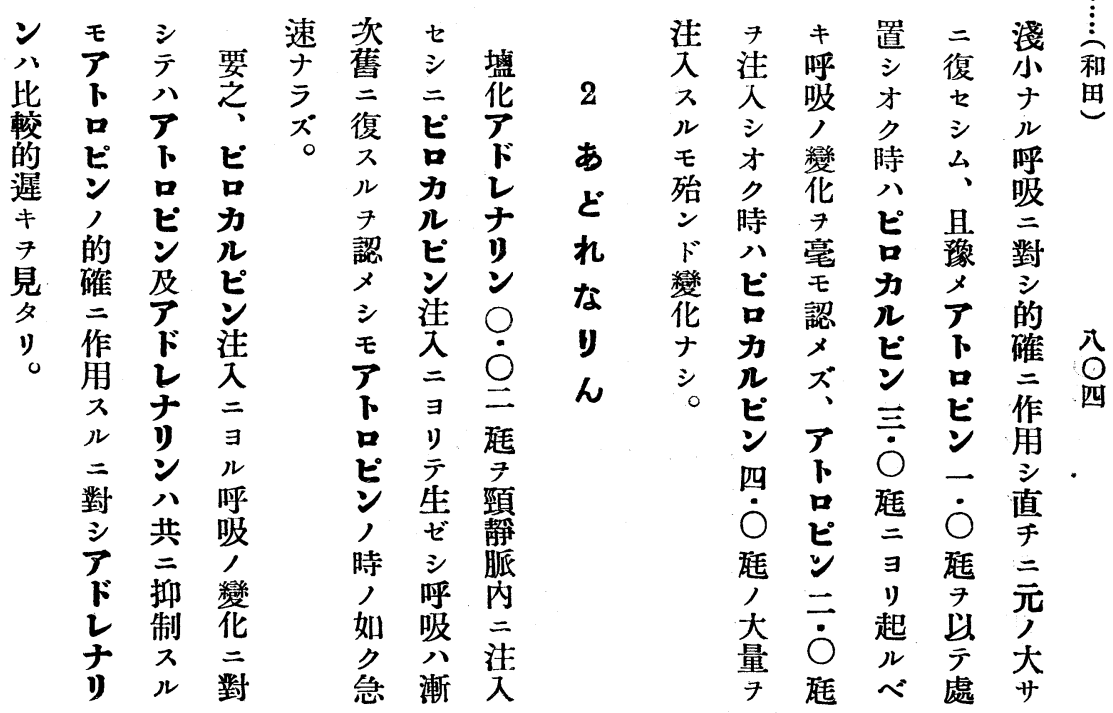




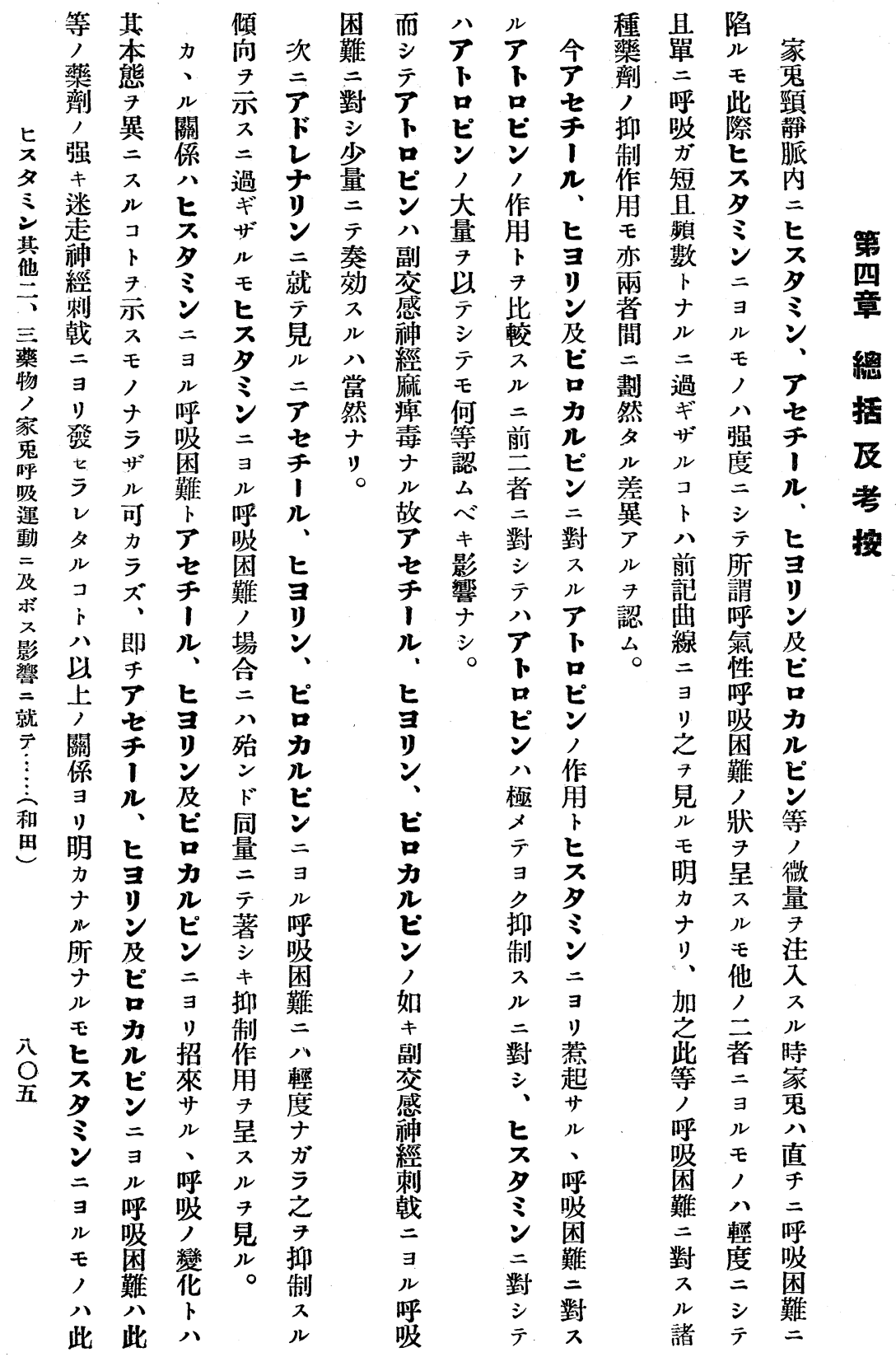




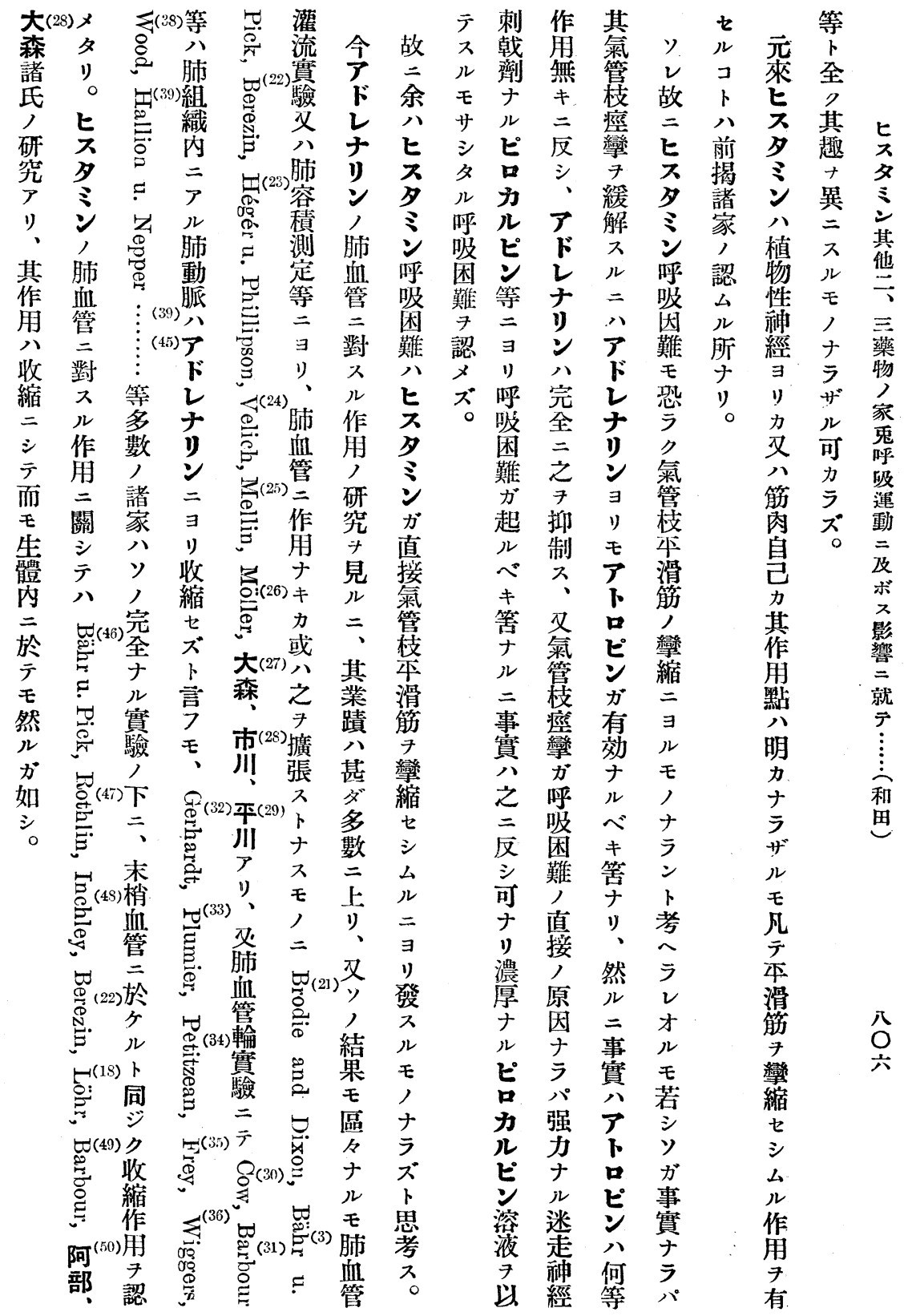




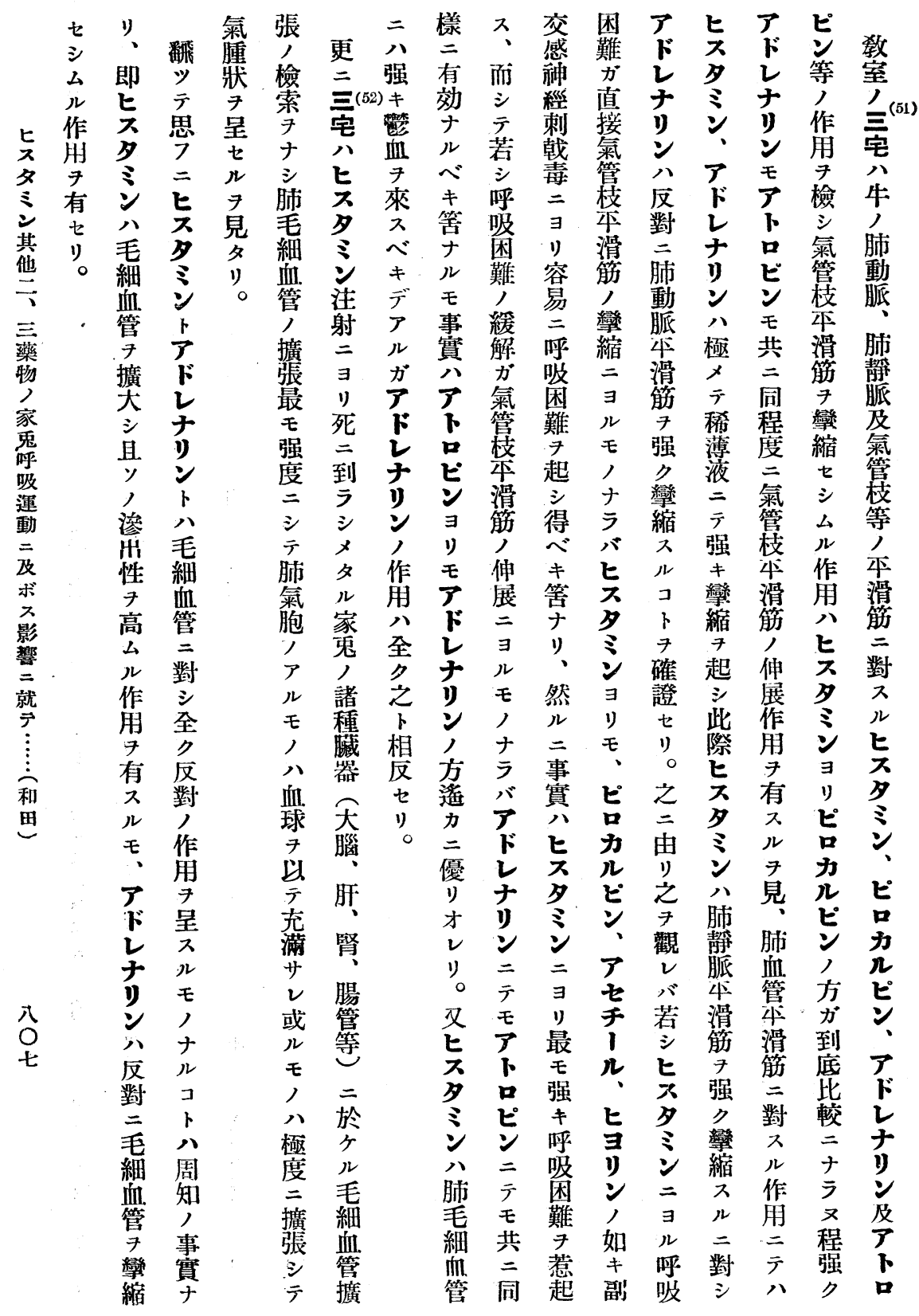




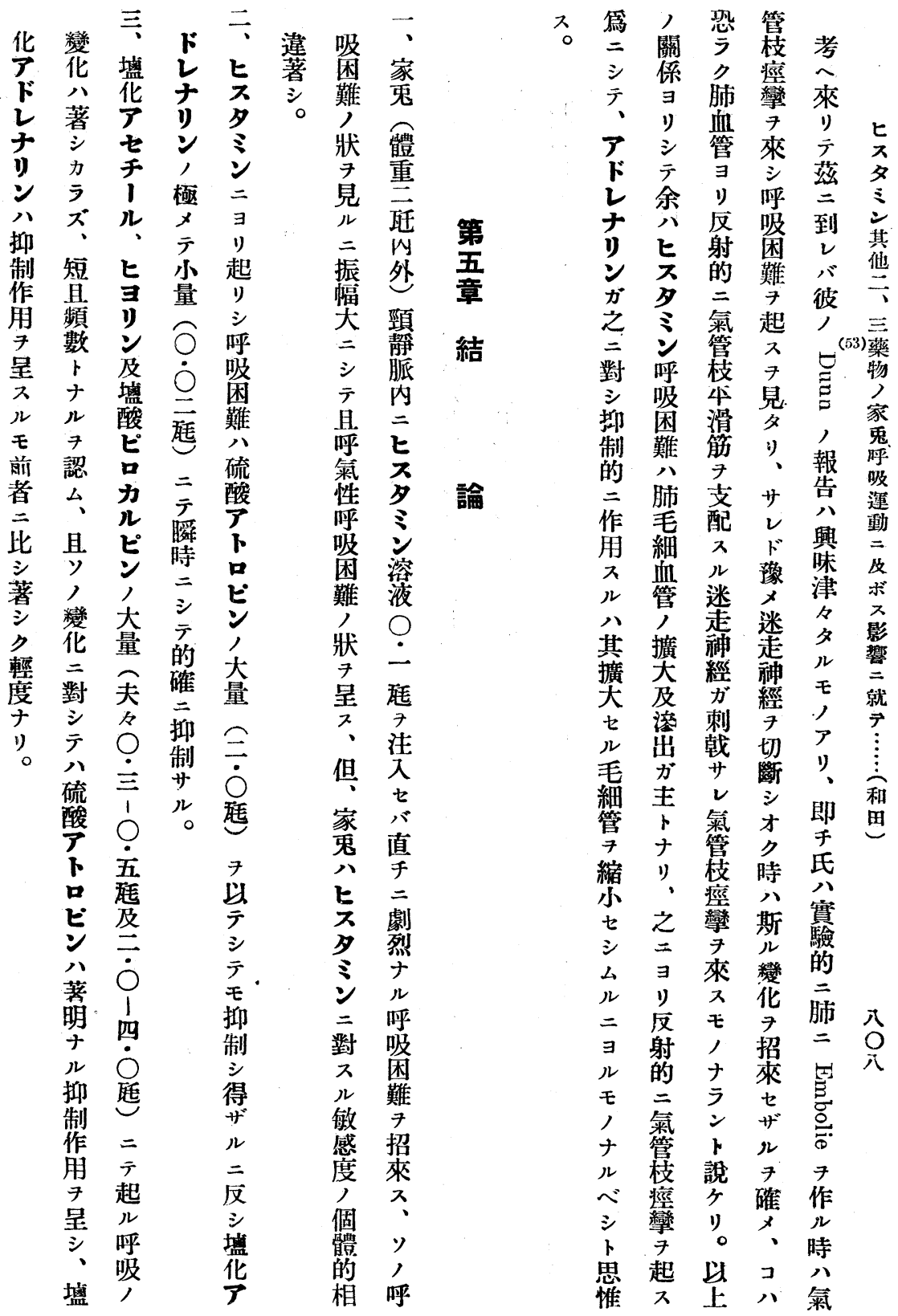




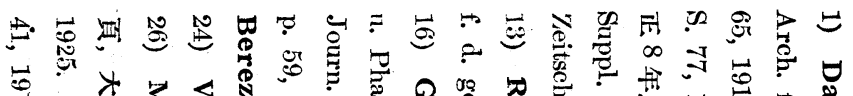

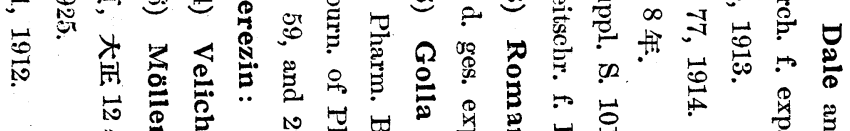

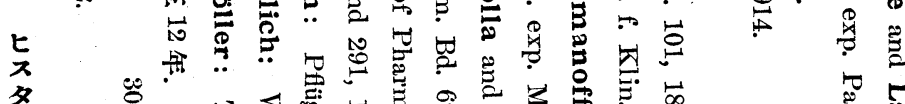

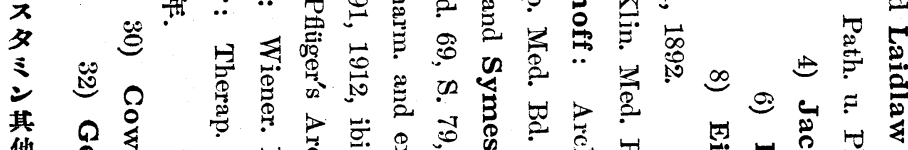

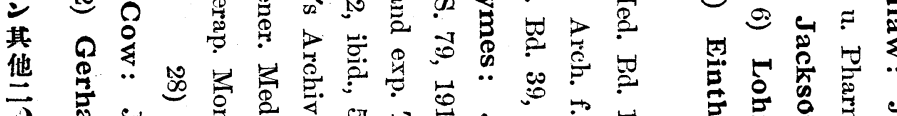

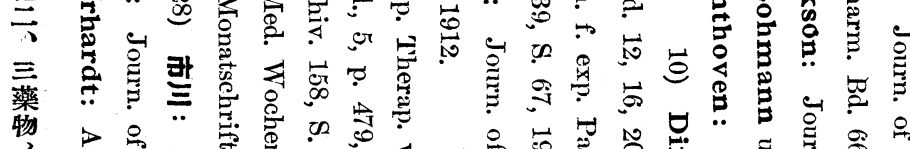

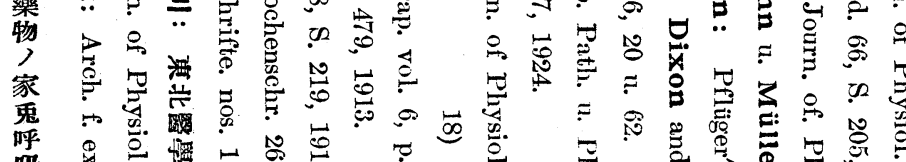

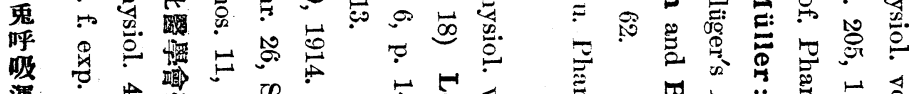

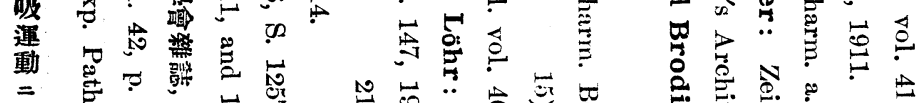
及

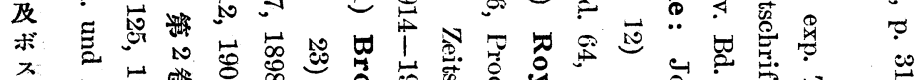

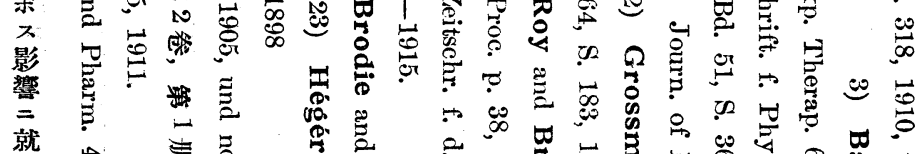

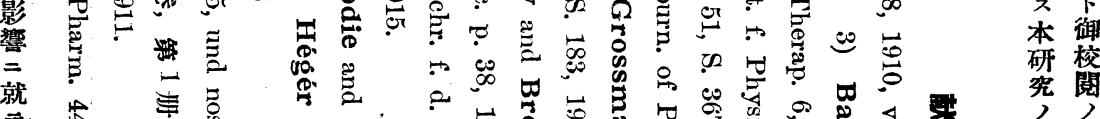

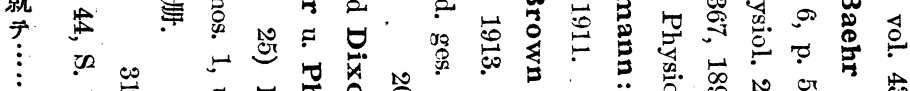

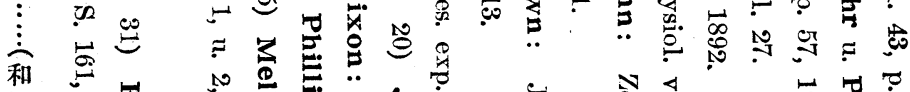

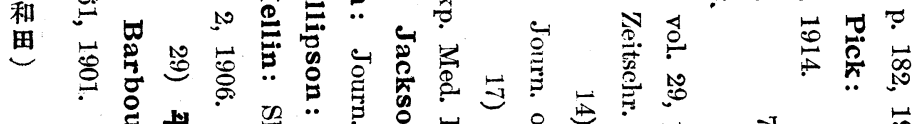

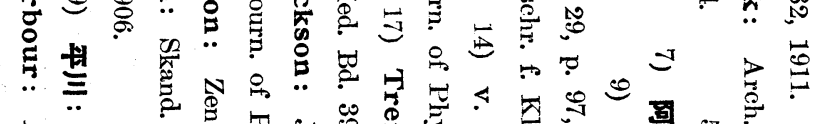

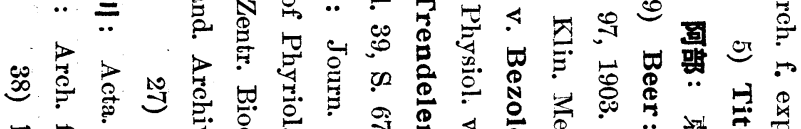
八.

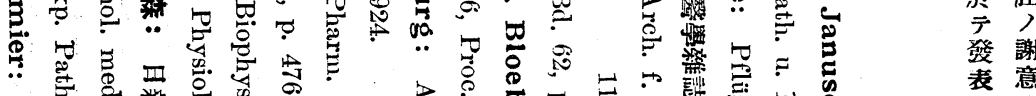

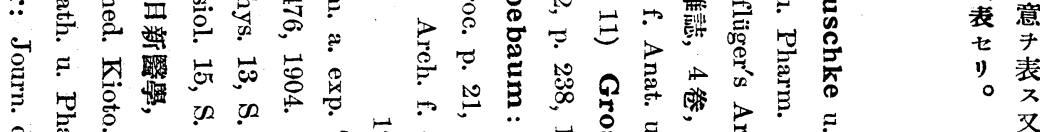

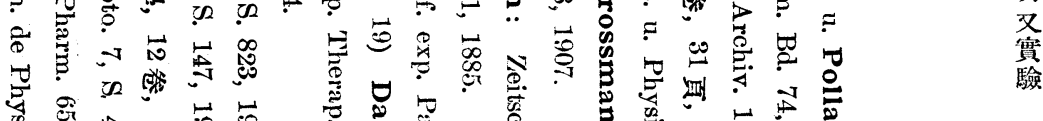

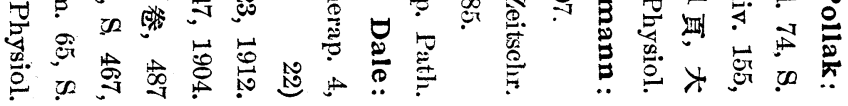

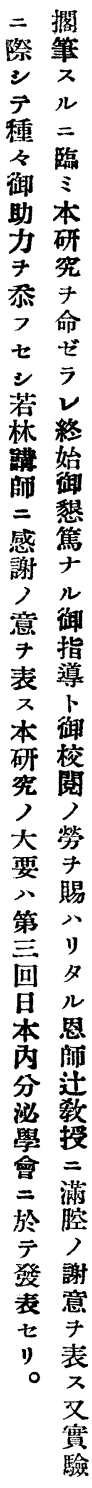




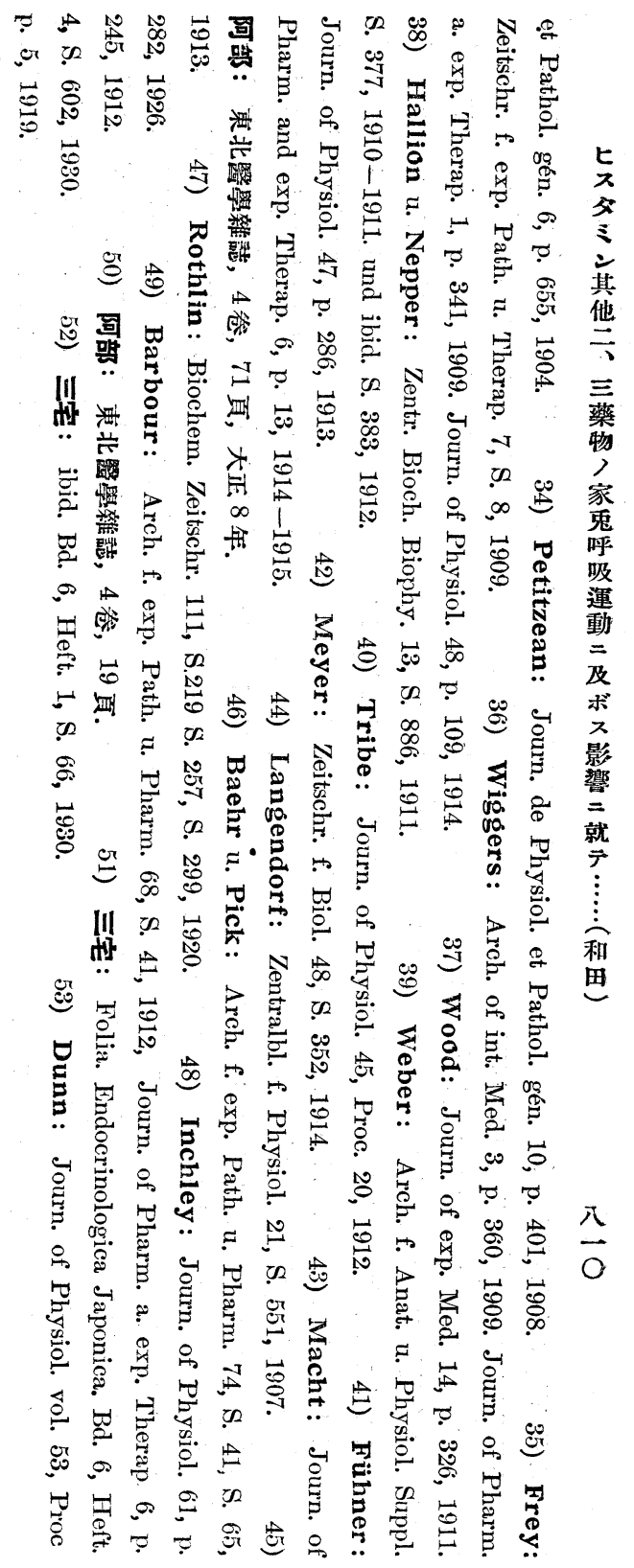




\title{
Ueber den Einfluss der Nebennierenrinde auf den Gaswechsel und die Beziehung zwischen Nebennierenrinde und Schilddrüse in Bezug auf denselben.
}

\author{
Von \\ Dr. S. Shinobe. \\ (Aus der I. med. Klinik der Kaiserl. Univers. zu Kyoto, Japan. \\ Direktor: Prof. Dr. K. Tsuji.)
}

Dieses Experiment wurde bei gesunden männlichen weissen Ratten vorgenommen. Die Gaswechselbestimmung wurde nach der modifizierten Foster-Sundstroemschen Methode ausgeführt.

Die Resultate sind wie folgt:

1) Wenn man die Ratten mit getrocknetem Nebennierenrindenpulver füttert, so sinkt der Sauerstoffverbrauch in leichtem Masse und zeigen die respiratorischen Quotienten keine Veränderungen.

2) Wenn man die Ratten mit getrocknetem Schilddrüsenpulver plus Nebennierenrindenpulver füttert, so nimmt das Körpergewicht weniger $a b$ und der Sauerstoffverbrauch weniger zu als bei den nur mit getrocknetem Schilddrüsenpulver gefütterten Kontrolltieren und zeigen die respiratorischen Quotienten keine deutlichen Veränderungen den Kontrolltieren gegenüber. Nach diesen Ergebnissen nimmt der Verfasser an, dass das Inkret der Schilddrüse und der Nebennierenrinde im entgegengesetzten Sinne auf den Gaswechsel wirkt.

(Autoreferat)

\section{Ueber den Einfluss von Histamin und einigen anderen Pharmaka auf die Atem- bewegung des Kaninchens.}

Von 
Dr. T. Wada.

(Aus der I. med. Klinik d. Kaiserl. Universität zu Kyoto, Japan. Direktor: Prof. Dr. K. Tsuji.)

Was die Entstehung des Bronchialasthmas anbetrifft, so nimmt man im allgemeinen an, dass es sich bei dieser Erkrankung um eine akute Verengerung der Bronchiolen handelt, die teils infolge des durch Vagotonie verursachten Bronchialkrampfes, teils infolge der durch dieselbe Ursache hervorgerufenen Anschwellung uud Sekretionszunahme der Bronchialschleimhaut zustande kommt. Die bisher angenommene Pathogenese lässt aber viele einzelne Symptome beim Bronchialasthma unerklärt.

So untersuchte der Verfasser die Entstehung der asthmaähnlichen Atemnot bei Tieren durch Histamininjektion. Er injizierte den Kaninchen (ca. $2.0 \mathrm{~kg}$ Gewicht) $0.1 \mathrm{mg}$ Histamin in physiologischer Kochsalzlösung in die Halsvenen, um das Mittel möglichst direkt auf die Lungenkapillaren wirken zu lassen. Sofort nach der Injektion trat eine heftige Atemnot auf. Die Respiration wurde tiefer und grösser, besonders aber wurde die Exspirationskurve höher.

Wurde eine grosse Dose Pilocarpin (2.0-4.0 mg) oder Acetylcholin (0.3-0.5 mg) injiziert, so stellte sich keine deutliche Atemnot ein und die Respiration wurde kürzer und dichter.

Die durch die Injektion von $0.1 \mathrm{mg}$ Histamin erzeugte Atemnot wurde durch die Injektion einer Atropinlösung (2.0 mg Atropin) nicht beeinflusst, wohingegen die Injektion einer Adrenalinlösung (0.02 mg Adrenalin) eine wunderbare Wirkung entfaltete. Sogleich nach der Adrenalininjektion stellte sich die normale Respiration wieder ein.

Die Atemveränderung durch Pilocarpin oder Acetylcholin wurde durch Atropinlösung deutlich beeinflusst, aber durch Adrenalinlösung nur schwach.

Da Histamin ein heftiges Kapillargift ist und insbesondere die Lungenkapillaren dadurch stark erweitert und gleichzeitig stark durchlässig werden, ist dasselbe wohl imstande, eine-typische asth- 
maartige Dyspnoe zu erzeugen. Dabei besteht die Wirkungsweise des Adrenalins zunächst in der Kontraktion der dilatierten Lungenkapillaren, der Hemmung der Transsudation derselben und endlich in der Lösung des Bronchospasmus.

(Autoreferat) 